\title{
FAKTOR-FAKTOR YANG BERPENGARUH TERHADAP KEJADIA ABORTUS INKOMPLIT DI RSUD GAMBIRAN KOTA KEDIRI TAHUN 2016
}

\author{
Mooren Lia Luthfiana, Triatmi Andri Yanuarini, Mika Mediawati \\ Prodi DIV Kebidanan Kediri Poltekkes Kemenkes Malang \\ Email: ytriatmiandri@yahoo.co.id
}

\begin{abstract}
Risk factors originating from the mother are maternal genetic abnormalities, age, parity, history of abortion, pregnancy interval, hormonal, maternal illness (anemia, infection, hypertension, kidney disease, liver disease, diabetes mellitus disease) and external influences such as medicine treatment, cigarettes, and others. The purpose of this study is to determine the factors that have an impact on the incidence of miscarriage in Gambiran Regional Public Hospital Kediri. This research used case control design. The population in this study were 198 maternal record data of women who had miscarriage and pregnant mothers until they gave birth. Sampling was done through simple random sampling and data collection using recapitulation of research data sheet instrument that was analyzed with Chi Square. The statistics test using Chi Square obtained $\chi$ value ${ }^{2}$ of $22.673>\chi^{2}$ table (at $\alpha 5 \%$ df 1) 3.841 so that $\mathrm{H}_{0}$ was rejected which means there is age effect on the incidence of miscarriage. On the parity variable the value was $21.134>\chi^{2}$ table (at $\alpha 5 \%$ df 1 ) 3.841 so that $H_{0}$ was rejected which means there is parity influence on miscarriage. At the pregnancy interval variable the value was 21.569> $\chi^{2}$ table (at $\alpha 5 \%$ df 1) 3.841 so that $H_{0}$ was rejected which means there is influence of pregnancy interval to miscarriage. In the abortion history variable the value was $1.992>\chi^{2}$ table (at $\alpha 5 \%$ df 1) 3.841 so that $H_{0}$ was accepted which means there is no effect of abortion history on miscarriage. Health workers are expected to share knowledge of the causes, prevention efforts and improve the quality of services in reducing miscarriage incidence.
\end{abstract}

Keyword: Factors, Miscarriage

\section{PENDAHULUAN}

Kehamilan merupakan hal yang fisiologis dialami oleh seorang wanita. Kehamilan adalah fertilisasi atau penyatuan dari spermatozoa dan ovum dan dilanjutkan dengan nidasi atau implantasi (Saifuddin, 2014). Lima penyebab kematian ibu terbesar yaitu perdarahan, hipertensi dalam kehamilan (HDK), infeksi, partus lama/macet, dan abortus.Kematian ibu di Indonesia masih didominasi oleh tiga penyebab utama kematian yaitu perdarahan, hipertensi dalam kehamilan (HDK), dan infeksi. Pada tahun 2013penyebab obstetrik langsung, terutama perdarahan $(30,2 \%)$, penyakit hipertensi kehamilan $(27,1 \%)$ dan sepsis $(7,3 \%)$ terus menjadi penyebab utama kematian ibu (Kemenkes RI, 2014).

Salah satu komplikasi terbanyak pada kehamilan ialah terjadinya perdarahan. Perdarahan dapat terjadi pada setiap usia kehamilan. Kejadian perdarahan pada kehamilan muda sering dikaitkan dengan abortus.Abortus adalah berakhirnya suatu kehamilan sebelum janin mencapai berat 500 gram atau umur kehamilan kurang dari 22 minggu atau buah kehamilan belum mampu untuk hidup diluar kandungan.Abortus spontan adalah abortus yangterjadi dengan tidak didahului faktorfaktor mekanis ataupun medisinalis, sematamatadisebabkan oleh faktor-faktor alamiah.Sekitar $15 \% \quad-20 \%$ terminasi 
kehamilan merupakanabortus spontan.Kalau dikaji lebih jauh kejadian abortus sebenarnya bisa mendekati $50 \%$.Hal ini dikarenakan tingginya angka chemical pregnancy loss yang tidak bisa diketahui pada 2-4 minggu setelah konsepsi.Sebagian besar kegagalan kehamilan ini dikarenakan kegagalan gamet (misalnya sperma dan disfungsi oosit) (Prawirohardjo, 2014).

Secara global $80 \%$ kematian ibu tergolong pada kematian langsung dimana aborsi berkonstribusi $13 \%$ terhadap Angka Kematian Ibu (AKI) tersebut. Diperkirakan terjadi aborsi illegal / tidak aman secara global sebanyak 20 juta orang/tahun atau 1 antara 10 kehamilan atau 1 aborsi tidak aman dengan 7 kelahiran hidup. Lebih dari 90\% aborsi tidak aman terjadi dinegara yang sedang berkembang.Di Indonesia aborsi tidak aman merupakan penyebab dari 11\% kematian ibu (Prawirohardjo, 2014). Pada tahun 2014 di Kota Kediri terdapat 106 ibu yang mengalami abortus dan pada tahun 2015 terdapat 117 ibu yang mengalami abortus. Selain itu juga peneliti mendapatkan data bahwa pada tahun 2016 terdapat 119 ibu yang mengalami abortus.Dari data tersebut dapat dilihat bahwa kejadian abortus pada setiap tahun mengalami peningkatan (Dinkes Kota Kediri, 2016).

Menurut Rahmani (2013) dalam Rochmawati (2014) bahwa: "Faktor-faktor yang mempengaruhi terjadinya abortus pada ibu hamil adalah usia, paritas, riwayat abortus, jarak kehamilan, sosial ekonomi, pendidikan, penyakit infeksi, alkohol, merokok, dan status perkawinan". Jarak kehamilan sangat mempengaruhi kesehatan ibu dan janin yang dikandungnya.Seorang ibu memerlukan waktu selama 2-3 tahun agar dapat pulih secara fisiologis dari satu kehamilan atau persalinan dan mempersiapkan diri untuk kehamilan berikutnya.Bila jarak kehamilan dengan anak sebelumnya kurang dari 2 tahun, rahim dan kesehatan ibu belum pulih dengan baik.4 Kehamilan dalam keadaan ini perlu diwaspadai karena ada kemungkinan pertumbuhan janin kurang baik, mengalami persalinan yang lama, atau perdarahan (abortus).

Usia menjadi indikator dalam kedewasaan dalam setiap pengambilan keputusan yang mengacu pada setiap pengalaman, usia yang cukup dalam mengawali atau memasuki usia perkawinan dan kehamilan akan membantu sesorang dalam kematangan menghadapi kesiapan terhadap masalah atau persoalan, dalam hal ini menghadapi kehamilan dan perubahan psikologis dan fisiologis selama hamil. Dimana semakin muda umur wanita maka semakin kurang perhatian serta pengalaman yang dimilki wanita usia subur karena ketidaksiapan wanita dalam menerima kehamilan dan sistem reproduksi yang belum matang. Hal ini berdampak pada psikologis wanita tersebut (Yuni, 2010). Pada proses menua terjadi mutasi gen sehingga risiko abortus spontan meningkat seiring dengan paritas serta usia ibu dan ayah. Insidensi abortus meningkat apabila wanita yang bersangkutan hamil dalam 3 bulan setelah melahirkan bayi aterm (Handono, 2009).

Studi pendahuluan yang dilakukan di RSUD Gambiran Kota Kediri didapatkan data yaitu pada tahun 2015 terdapat 203 kejadian abortus dan pada tahun 2016 terdapat 227 kejadian abortus. Pada tahun 2015 terdapat 43 kejadian abortus inkomplit dan pada tahun 2016 terdapat 58 kejadian abortus inkomplit. Untuk kejadian abortus spontan lainnya yaitu terdapat 23 kejadian abortus komplit, 17 kejadian abortus imminens dan 20 kejadian abortus habitualis. Sedangkan untuk tindakan penanganan abortus di RSUD Gambiran pada tahun 2016 terdapat sebanyak 55 curretage. Pada tahun 2015 terdapat 47 kejadian HPP dan 7 ibu nifas yang mengalami infeksi sedangkan pada tahun 
2016 didapatkan data 30 kejadian HPP dan 4 ibu nifas yang mengalami infeksi.

Perlunya penanganan yang baik dan tepat terhadap abortus pada ibu hamil, dimana masyarakat khususnya wanita lebih mengenal masalah yang berkaitan dengan abortus, hal - hal yang dapat menyebabkan terjadinya abortus dan komplikasinya serta bagaimana cara mencegah agar kejadian tersebut tidak terjadi atau terulang lagi pada kehamilan berikutnya dan nantinya diharapkan anak akan lahir dengan selamat, sehat serta diharapkan dapat menurunkan angka kejadian abortus (Yono, 2011). Sejalan dengan Peraturan Pemerintah Republik Indonesia Nomor 87 Tahun 2014 yaitu program Keluarga Berencana (KB) merupakan salah satu strategi untuk mengurangi kematian ibu khususnya ibu dengan kondisi 4T; terlalu muda melahirkan (di bawah usia 20 tahun), terlalu sering melahirkan, terlalu dekat jarak melahirkan, dan terlalu tua melahirkan (di atas usia 35 tahun). Selain itu, program $\mathrm{KB}$ juga bertujuan untuk meningkatkan kualitas keluarga agar dapat timbul rasa aman, tentram, dan harapan masa depan yang lebih baik dalam mewujudkan kesejahteraan lahir dan kebahagiaan batin.

Dari paparan latar belakang tersebut peneliti tertarik untuk melakukan penelitian tentang "Faktor-faktor apa sajakah yang mempengaruhi kejadian abortus inkomplit di RSUD Gambiran Kota Kediri”.

\section{METODE PENELITIAN}

Desain yang digunakan dalam penelitian ini adalah Case Control.Populasi dalam penelitian ini adalah 198 data rekam medic ibu yang mengalami abortus inkomplit dan ibu hamil sampai melahirkan.Sampel dalam peneltian sejumlah 95.

Variabel independen dalam penelitian ini adalah faktor-faktor yang berpengaruh, antara lain: usia, interval kehamilan, paritas dan riwayat abortus. Variabel dependen dalam penelitian ini adalah kejadian abortus.Pengambilan sampel melalui simple random sampling dan pengumpulan data menggunakan instrument lembar rekapitulasi data penelitian yang dianalisis dengan Chie Square.

\section{HASIL PENELITIAN}

Berdasarkan rekam medik pasien, diperoleh data yang terdiri dari kejadian abortus inkomplit, usia, paritas, interval kehamilan, dan riwayat abortus. Kemudian data pengaruh usia terhadap kejadian abortus inkomplit, pengaruh paritas terhadap kejadian abortus inkomplit, pengaruh interval kehamilan terhadap kejadian abortus inkomplit dan pengaruh riwayat abortus terhadap kejadian abortus inkomplit diuji dengan Chi Square yang disajikan dalam bentuk tabel kontingensi atau tabulasi silang.

Tabel 4.1 Distribusi frekuensi usia, paritas, interval kehamilan dan riwayat abortus pada kejadian abortus inkomplit di RSUD Gambiran Kota Kediri periode 1 Juli - 31 Desember 2016

\begin{tabular}{|c|c|c|}
\hline Variabel Independen & Jumlah & Persentase \\
\hline \multicolumn{3}{|l|}{ Usia } \\
\hline Beresiko & 25 & 69,4 \\
\hline Tidak Beresiko & 11 & 30,6 \\
\hline \multicolumn{3}{|l|}{ Paritas } \\
\hline Beresiko & 21 & 58,3 \\
\hline Tidak Beresiko & 15 & 41,7 \\
\hline \multicolumn{3}{|l|}{ Interval Kehamilan } \\
\hline$<2$ tahun & 26 & 72,2 \\
\hline$>2$ tahun & 10 & 27,8 \\
\hline \multicolumn{3}{|l|}{ Riwayat Abortus } \\
\hline $\begin{array}{l}\text { Memiliki } \quad \text { Riwayat } \\
\text { Abortus }\end{array}$ & 9 & 25,0 \\
\hline $\begin{array}{l}\text { Tidak Memiliki Riwayat } \\
\text { Abortus }\end{array}$ & 27 & 75,0 \\
\hline $\begin{array}{l}\text { Sumber: Data Rekam Me } \\
\text { Berdasarkan tabel } \\
\text { bahwa dari } 36 \text { data rek } \\
\text { mengalami abortus } \\
\text { besar }(69,4 \%) \text { berada pa }\end{array}$ & $\begin{array}{l}\text { ik } \\
\text { m medil } \\
\text { komplit } \\
\text { la rentan }\end{array}$ & $\begin{array}{l}\text { diketahui } \\
\text { ibu yang } \\
\text { sebagian } \\
\text { usia }<20\end{array}$ \\
\hline
\end{tabular}


Tabel 4.5 Tabulasi silang pengaruh riwayat abortus terhadap kejadian abortus inkomplit di RSUD Gambiran Kota Kediri periode 1 Juli - 31 Desember 2016.

\begin{tabular}{|c|c|c|c|c|c|}
\hline \multirow[b]{2}{*}{$\begin{array}{l}\text { Riwayat } \\
\text { Abortus }\end{array}$} & \multicolumn{2}{|c|}{ Kejadian Abortus } & \multirow[b]{2}{*}{ Jumlah } & \multirow{2}{*}{$\begin{array}{c}\chi^{2} \\
\text { hit } \\
\text { un } \\
\mathrm{g}\end{array}$} & \multirow[b]{2}{*}{$\begin{array}{c}\rho \\
\text { value }\end{array}$} \\
\hline & $\begin{array}{l}\text { Abortus } \\
\text { Inkomplit } \\
\text { (kasus) }\end{array}$ & $\begin{array}{c}\text { Tidak } \\
\text { Abortus } \\
\text { (kontrol) }\end{array}$ & & & \\
\hline $\begin{array}{c}\text { Memiliki } \\
\text { Riwayat } \\
\text { Abortus } \\
\text { Tidak }\end{array}$ & $\begin{array}{c}9 \\
(25,0 \%)\end{array}$ & $\begin{array}{c}8 \\
(13,6 \%)\end{array}$ & $\begin{array}{c}17 \\
(17,9 \%)\end{array}$ & $\begin{array}{c}1, \\
99 \\
2\end{array}$ & $\begin{array}{c}0,15 \\
8\end{array}$ \\
\hline $\begin{array}{l}\text { Memiliki } \\
\text { Riwayat } \\
\text { Abortus }\end{array}$ & $\begin{array}{c}27 \\
(75,0 \%)\end{array}$ & $\begin{array}{c}51 \\
(86,4 \%)\end{array}$ & $\begin{array}{c}78 \\
(82,1 \%)\end{array}$ & & \\
\hline Jumlah & $\begin{array}{c}36 \\
(100 \%)\end{array}$ & $\begin{array}{c}59 \\
(100 \%)\end{array}$ & $\begin{array}{c}95 \\
(100 \%)\end{array}$ & & \\
\hline
\end{tabular}

Sumber : Data Rekam Medik

Berdasarkan analisis data menggunakan uji statistic dengan chie square SPSS seri 19 dengan $\alpha 0,05$ dan perhitungan secara manual didapatkan hasil bahwa hasil nilai $\rho$ value adalah 0,158 sehingga bila dibandingkan dengan $\alpha 0,05$ adalah $0,158>$ 0,05 artinya $\mathrm{H}_{0}$ diterima sehingga menunjukkan bahwa tidak ada pengaruh riwayat kehamilan terhadap kejadian abortus inkomplit.

\section{PEMBAHASAN}

Menganalisis Pengaruh Usia Terhadap Kejadian Abortus Inkomplit

Hasil penelitian ini sesuai dengan penelitian yang dilakukan oleh Mardiana dkk (2014) tentang Usia Ibu Hamil Terhadap Paritas Dengan Kejadian Abortus di RSUD dr.Agoesdjam Ketapang menunjukkan bahwa terdapat hubungan antara usia ibu hamil dengan kejadian abortus dengan nilai $\mathrm{x} 2$ hitung $=20,981$. Hasil perhitungan $\mathrm{OR}=4,304$ menunjukkan bahwa usia<20 tahun atau $>35$ tahun mempunyai kemungkinan 4,304 kali lebih besar untuk mengalami abortus jika dibandingkan dengan ibu yang berusia 2035 tahun.

Menurut Cunningham (2014) bahwa keguguran simtomatik meningkat seiring dengan usia ibu dan ayah. Frekuensi berlipat dua dari $12 \%$ pada wanita berusia kurang dari 20 tahun menjadi 26 persen pada mereka yang berusia lebih dari 40 tahun. Menurut Mochtar (2013) wanita yang hamil pada usia terlalu muda yaitu dibawah umur 20 tahun secara fisik alat-alat reproduksi belum berfungsi dengan sempurna dan belum siap untuk menerima hasil konsepsi sehingga bila terjadi kehamilan dan persalinan akan lebih mudah mengalami komplikasi dan secara psikologis belum cukup dewasa dan matang untuk menjadi seorang ibu.

Hal ini dikaitkan juga dengan umur ibu primipara yang kebanyakan menikah pada usia<20 tahun dan langsung hamil anak pertama, pada usia ini organ reproduksi belum berkembang sempuma (Rahayu, 2010). Wanita dengan usia lebih dari 35 tahun juga memiliki peluang lebih besar mengalami masalah medis umum yang mungkin juga akan mempengaruhi janin yang sedang tumbuh dan berkembang. Beberapa masalah memerlukan pengobatan yang mungkin tidak sesuai untuk wanita hamil. Calon ibu juga merasakan cepat kelelahan dan kekurangan tenaga selama proses melahirkan. Kehamilan juga bisa memperburuk kondisi-kondisi medis ringan seperti sakit punggung atau anemia, karena beban yang ditimbulkan selama sang ibu hamil. Faktor-faktor resiko lainnya juga berpengaruh dalam kehamilan ibu yang berusia lebih dari 35 tahun, diantaranya bisa menyebabkan keguguran (Nirwana, 2011).

Di Indonesia masih tingginya jumlah perkawinan usia muda kurang dari 20 tahun dan masih banyak yang hamil pada usia diatas 35 tahun. Sehingga mempengaruhi status biologis wanita itu sendiri, dimana jika wanita hamil dalam usia tersebut maka dapat membahayakan dirinya dan janin yang dikandungnya (Manuaba, 2010). 
Menganalisis Pengaruh Paritas Terhadap Kejadian Abortus Inkomplit

Hasil penelitian ini menunjukkan bahwa ada pengaruh paritas terhadap kejadian abortus inkomplit.Berdasarkan hasil penelitian dan melihat penelitian sebelumnya, serta berdasarkan pendapat para ahli maka peneliti menyimpulkan bahwa ibu hamil pertama kali atau >4 merupakan faktor risiko terjadinya abortus pada kehamilan, sedangkan ibu yang memiliki paritas 1-4 merupakan kondisi aman untuk ibu yang menginginkan kehamilan sehingga dapat mengurangi risiko terjadinya abortus.Namun karena faktor risiko terjadi keguguran tidak hanya ditinjau dari paritas maka dianjurkan untuk ibu yang menginginkan kehamilan untuk melakukan konseling terhadap petugas kesehatan.

Dengan demikian ibu yang memiliki paritas tinggi atau Grandemultipara beresiko terjadinya abortus. Angka kejadian pada hasil penelitian menunjukkan bahwa banyak terdapat abortus pada multipara dan semakin tinggi kejadiannya pada grandemultipara.Kejadian abortus pada ibu pada paritas tinggi berkaitan dengan keadaan endometrium di daerah korpus uteri sudah mengalami kemunduran fungsi dan berkurangnya vaskularisasi.Hal ini terjadi karena degenerasi dan nekrosis pada berkas luka implantasi plasenta sewaktu kehamilan sebelumnya di dinding endometrium. Ibu yang sering melahirkan juga akan mengalami kekendoran pada dinding parut dan dinding rahim sehingga dapat menyebabkan keguguran.

\section{Menganalisis Pengaruh Interval Kehamilan Terhadap Kejadian Abortus Inkomplit}

Hasil penelitian menunjukkan ada pengaruh interval kehamilan terhadap kejadian abortus inkomplit di RSUD Gambiran Kota Kediri.
Hasil penelitian ini sesuai dengan penlitian yang dilakukan oleh Pitriani, R. (2013) tentang faktor- faktor yang berhungan dengan kejadian abortus di Rumah sakit Umum Daerah Arifin Achmad Provinsi Riau yang menyatakan bahwa terdapat hubungan antara jarak kehamilan dengan kejadian abortus. Hasil $\mathrm{OR}=2,084$ menunjukkan bahwa interval kehamilan $<2$ tahun menyebabkan 2,084 kali lebih besar terjadinya abortus inkomplit daripada interval kehamilan $>2$ tahun.

Hasil penelitian inipun juga sesuai dengan pendapat yang dikemukakan Krisnadi dalam Vita (2015) bahwa jarak kehamilan dengan anak sebelumnya kurang dari 2 tahun, rahim dan kesehatan ibu belum pulih dengan baik. Kehamilan dalam keadaan ini perlu diwaspadai karena ada kemungkinan pertumbuhan janin kurang baik, mengalami persalinan yang lama, atau perdarahan (abortus).

Menurut Saifuddin (2014) mengatakan bahwa kehamilan sebelum 2 tahun sering mengalami komplikasi dalam kehamilan.Kesehatan fisik dan rahim ibu masih butuh cukup istirahat, ada kemungkinan ibu masih menyusui, selain itu anak tersebut masih butuh asuhan dan perhatian orang tuanya. Bahaya yang mungkin terjadi bagi ibu antara lain perdarahan setelah bayi lahir karena kondisi ibu masih lemah, bayi premature,bayi BBLR < 2500 gram, dan bisa juga terjadi keguguran.

Pada involusi uteri, jaringan ikat dan jaringan otot mengalami proses preteolitik, berangsur-angsur akan mengecil sehingga pada akhir kala nifas besarnya seperti semula dengan berat 30 gram. Waktu yang dibutuhkan uterus untuk kembali dalam ukuran normal biasanya 56 hari dengan berat 30 gram.Dimana pada saat itu tinggi fundus sudah kembali normal.Sebaiknya masyarakat dianjurkan untuk melakukan pemeriksaan postpartum, sehingga alat repsoduksinya cukup sehat, untuk menjadi 
hamil dengan interval yang dikehendaki dimana kesehatan reproduksi yang optimal yaitu dengan interval lebih dari 2 tahun (Manuaba, 2010).

\section{Menganalisis Pengaruh Riwayat Abortus Terhadap Kejadian Abortus Inkomplit}

Pada penelitian ini, didapatkan hasil yang menunjukkan bahwa tidak ada pengaruh riwayat abortus terhadap kejadian abortus inkomplit.Hal ini tidak sesuai dengan pendapat yang dijelaskan oleh Prawirohardjo (2014) bahwa riwayat abortus pada penderita abortus merupakan predisposisi terjadinya abortus berulang.Kejadiannya sekitar 3-5\%. Data dari beberapa studi menunjukkan bahwa setelah 1 kali abortus pasangan punya resiko $15 \%$ untuk mengalami keguguran lagi, sedangkan bila pernah 2 kali, resikonya akan meningkat $25 \%$. Beberapa studi meramalkan bahwa resiko abortus setelah 3 kali abortus berurutan adalan 30$45 \%$.

Dalam pemeriksaan awal kehamilan sangat penting untuk dilakukan anamnesa mengenai riwayat kesehatan yang lalu terutama mengenai riwayat kehamilan yang lalu. Dalam KSPR menunjukan bahwa jika seorang wanita pernah gagal hamil maka akan mendapatkan skor 4. Menurut Manuaba (2010) disebutkan bahwa keadaan yang dapat membahayakan saat hamil dan meningkatkan bahaya terhadap janin yaitu sejarahpersalinan yang buruk : pernah keguguran dan persalinan premature, kelahiran dengan BBLR dan pernah mengalami persalinan dengan tindakan (Manuaba, 2010).

Risiko terjadinya abortus spontan meningkat bersamaan dengan peningkatan jumlah paritas, usia ibu, jarak persalinan dengan kehamilan berikutnya. Abortus meningkat sebesar $12 \%$ pada wanita usia kurang dari 20 tahun dan meningkat sebesar $26 \%$ pada usia lebih dari 40 tahun. Insiden terjadinya abortus meningkat jika jarak persalinan dengan kehamilan berikutnya 3 bulan (Cunningham, 2014).

Sebagian besar wanita dengan keguguran berulang mengalami kematian mudigah atau janin dini, dan sebagian kecil keguguran setelah 14 minggu.Keguguran berulang perlu dibedakan dari keguguran aporadik.Keguguran aporadik mengisyaratkan bahwa ada kehamilan di antara keguguran yang menghasilkan bayi sehat.Beberpa penulis membedakan keguguran berulang primer-belum pernah mengalami kehamilan yang sukses-dari keguguran berulang sekunder-pernah melahirkan bayi hidup-karena kelompok yang terakhir ini tidak mengalami resiko keguguran berikutnya sebesar 32\% sampai setelah 3 kali keguguran (Cunningham, 2014).

Pada satu penelitian menyatakan bahwa kariotipe normal teridentifikasi pada separuh dari keguguran berulang tetapi hanya pada sepermpat dari keguguran sporadic.Waktu terjadinya keguguran mungkin memberi petunjuk tentang kausa. Pada contoh lain, faktor genetik tersering menyebabkan kematian mudigah dini, sementara penyakit autoimun atau anatomis lebih besar kemungkinannya menyebabkan keguguran trimester kedua (Schust dan Hill (2002) dalam Cunningham, 2014).

Menurut Prawirohardjo (2014) bahwa riwayat abortus pada penderita abortus merupakan predisposisi terjadinya abortus berulang.Kejadiannya sekitar 3-5\%. Data dari beberapa studi menunjukkan bahwa setelah 1 kali abortus pasangan punya resiko $15 \%$ untuk mengalami keguguran lagi, sedangkan bila pernah 2 kali, resikonya akan meningkat $25 \%$. Beberapa studi meramalkan bahwa resiko abortus setelah 3 kali abortus berurutan adalan 30$45 \%$.

Pada penelitian ini tidak terdapat pengaruh abortus sebelumnya tehadap kejadian abortus inkomplit.Namun peneliti beramsumsi bahwa ketidak sesuaian hasil 
uji analisis karena dari semua ibu yang mengalami abortus inkomplit ternyata sebagian besar adalah ibu Primigravida atau primipara dimana ibu tersebut hamil pertama kali sehingga tercatat tidak memiliki riwayat abortus.Hal tersebut yang mempengaruhi hasil analisis dimana pada hasil uji Chie Square tidak ada pengaruh riwayat abortus terhadap kejadian abortus inkomplit.

Pada ibu yang memiliki paritas $>1$ yang mengalami abortus inkomplit sebagian besar memiliki riwayat abortus dan sebagian kecil tidak memiliki riwayat abortus.Pada ibu yang tidak mengalami abortus inkomplit bahwa hampir seluruhnya tidak memiliki riwayat abortus sebelumnya.Sehingga peneliti berasumsi bahwa sebenarnya sesuai dengan pendapat beberapa ahli bahwa riwayat abortus merupakan faktor terjadinya abortus inkomplit.

Seorang wanita yang memiliki riwayat abortus merupakan suatu keadaan yang dapat membahayakan saat hamil dan meningkatkan bahaya terhadap janin salah satunya yaitu keguguran. Kariotipe normal teridentifikasi pada separuh dari keguguran berulang tetapi hanya pada sepermpat dari keguguran sporadic.Waktu terjadinya keguguran mungkin memberi petunjuk tentang kausa. Pada contoh lain, faktor genetik tersering menyebabkan kematian mudigah dini, sementara penyakit autoimun atau anatomis lebih besar kemungkinannya menyebabkan keguguran trimester kedua.

\section{KESIMPULAN}

1. Ada pengaruh usia terhadap kejadian abortus inkomplit.

2. Ada pengaruh paritas terhadap kejadian abortus inkomplit pada ibu hamil di RSUD Gambiran Kota Kediri.

3. Ada pengaruh interval kehamilan terhadap kejadian abortus inkomplit pada ibu hamil di RSUD Gambiran Kota Kediri.
4. Tidak ada pengaruh riwayat abortus terhadap kejadian abortus inkomplit pada ibu hamil di RSUD Gambiran Kota Kediri.

\section{Saran}

1. Bagi Peneliti

Diharapkan dapat lebih meningkatkan upaya promotif melalui penyuluhan kesehatan tentang Keluarga Berencana $(\mathrm{KB})$ dan penyuluhan kepada masyarakat khususnya wanita tentang faktor-faktor yang berpengaruh terhadap kejadian abortus inkomplit dengan menggunakan leaflet sebagai salah satu upaya pencegahan terjadinya abortus inkomplit.

2. Bagi Tenaga Kesehatan

Diharapkan hasil penelitian dapat menambah pengetahuan dan pemahanan tentang faktor-faktor yang berpengaruh terhadap kejadian abortus inkomplit, serta dapat meningkatkan upaya pencegahan terjadinya abortus inkomplit dengan memberikan asuhan kebidanan sesuai SOP yang berdasarkan evidence based.

3. Bagi Masyarakat

Diharapkan hasil penelitian ini dapat dipahami oleh masyarakat sehingga masyarakat mengetahui tentang faktorfaktor yang berpengaruh terhadap kejadian abortus inkomplit, serta memacu masyarakat untuk memiliki keinginan untuk mengikuti berbagai penyuluhan tentang abortus inkomplit.

DAFTAR PUSTAKA

Anonim. 2013. Buku Saku Pelayanan Kesehatan Ibu DI Fasilitas Kesehatan Dasar Dan Rujukan. Jakarta.

Anonim. 2015. Profil Kesehatan Indonesia 2015. Jakarta: Kemenkes RI

Anonim. 2016. Profil Kesehatan Indonesia 2016. Jakarta: Kemenkes RI 
Anwar, M. 2014. Ilmu Kandungan Edisi Ketiga. Jakarta: P.T. Bidan Pustaka Sarwono Prawirohardjo.

Arikunto, S. 2006. Prosedur Penelitian Suatu Pendekatan Praktik. Jakarta: Rineka Cipta.

Baba.S., dkk.Risk Factor of Early Spontaneous Abortion Among Japanese: a Matched Case Control Study. Human Reproduction.2010 December 14; Vol.26 pp. 466472.Diakses pada Tangaal 13 Juli 2017.

Chamberlain, G. Dan Morgan, M., 2013.Asuhan Antenatal edisi 4. Jakarta: Penerbit EGC

Cuningham, Dkk, 2014. Obstetri William. Jakarta: EGC

Dede, M. 2013. Jurnal.Hubungan Paritas dengan Kejadian Abortusbdi Ruang Bersalin RSUD dr. H. Moch. Anshari Saleh Banjarmasin. Banjarmasin: Dinamika Kesehatan, Vol. 12 No. 17, diakses pada tanggal 10 Juli 2017

Dina. N. L. 2015. Jurnal.Faktor Resiko yang Berhubungan dengan Kejadian Abortus Spontan di RSUD Ungaran Kabupaten Semarang.A Matched Case-Control.Humn Reproduction 2015 juli.Semarang : Program Study DIV Kebidanan STIKES Ngudi Waluyo Ungaran. Diakses pada 10 Juli 2017.

Fajriya, L. 2013. Analisis Faktor Resiko Kejadian Abortus di RSUD Dr. M.Djamil Padang.Jurnal Keseperawatan Volume 9, No 2.Diakses pada tanggal 27 Agustus 2017.

Handayani, E. Y. 2015. Hubungan Umur dan Paritas Dengan Kejadian Abortus Di RSUD Kabupaten Rokan Hulu.Universitas Pasir Pengaraian. Diakses Pada tanggal 13 Juli 2017.

Halim, R., dkk. 2014. Karakteristik Penderita Abortus Inkomplit Di RSUD DR. Pirngadi Kota Medan
Tahun 2010-2011. Fakultas Kesehatan Masyarakat Universitas Sumatra Utara.Diakses pada 11 Juli 2017.

Hardjito, K. 2011. Pengantar Biostatistika. Magetan: Forum Ilmu Kesehatan Hidayat, A. A. A. 2007. Metode Penelitian Kebidanan dan Teknik Analisis Data.Jakarta: Salemba Medika

Lukitasari, E. 2010.Kejadian Abortus Inkomplitus yang Berkaitan dengan Faktor Risiko pada Ibu Hamil di RSU.H.M Ryacudu Kotabumi Kabipaten Lampung Utara Tahun 2007-2009.Skripsi Fakultas Kesehatan Masyarakat Universitas Indonesia.Diakses pada tanggal 15 Juli 2017.

Mansjoer. 2010. Kapita Selekta Kedokteran. Jakarta: Media Aesculapius

Manuaba, I. 2010. Ilmu Kebidanan, Penyakit Kandungan, dan KB. Jakarta: Penerbit IGC

Manuaba, I. B. G., dkk. 2010. Pengantar Kuliah Obstetri. Jakarta: Penerbit EGC

Mardiani, dkk. 2014. Usia Ibu Hamil Terhadap Paritas Dengan Kejadian Abortus Di RSUD Dokter Agoesdjam Ketapang.Poltekes Kemenkes Pontianak Jurusan Kebidanan.Diakses pada 16 Juli 2017.

Marmi, A. R. M. S, dkk. 2011. Asuhan Kebidanan Patologi. Yogyakarta: Pustaka Pelajar

-----------------. 2012. Intranatal Care Asuhan Kebidanan Pada Persalinan. Yogyakarta: Pustaka Pelajar

Medforth, J. dan Susan , dkk. 2011. Kebidanan Oxford: Dari Bidan untuk Bidan. Jakarta: EGC

Mochtar, R. 2011. Sinopsis Obstetric. Jakarta: Penerbit EGC

Mochtar, R. 2015. Sinopsis Obstetric. Jakarta: Penerbit EGC

Nuraini, D., dkk. 2016. Faktor-faktor Yang Berpengaruh Dengan Kejadian Abortus Di RSUD Kelet Kabupaten 
Jepara Provinsi Jawa Tengah. DIakses pada tanggal 20 Juli 2017.

Nirwana, A. 2011.Kapita Selekta Kehamilan. Cetakan I. Yogyakarta: Nuha Medika.

Notoatmodjo, S. 2010. Metodologi Penelitian Kesehatan. Jakarta : Rineka Cipta

Nursalam. 2008. Konsep dan Penerapan Metodologi Penelitian Ilmu Keperawatan pedoman skripsi, tesis, dan instrument penelitian keperawatan. Jakarta: Salemba Medika

Oxorn, H \& William R. F. 2010.Ilmu kebidanan: Patologi \& Fisiologi Persalinan. Yogyakarta: Yayasan Essentia Medika

Pitriani, R. 2013. Faktor-faktor yang Berhubungan Dengan Abortus Inkomplit Di RSUD Arifin Achmad Provinsi Riau.Jurnal Kesehatan Komunitas, Vol.2, No.2, Diakses pada tanggal 15 Agustus 2017.

Prawirohardjo, S. 2014. Ilmu Kebidanan. Jakarta: PT Bina Pustaka Sarwono Prawirohardjo

Prawirohardjo, S. 2010. Ilmu Kebidanan. Jakarta: PT Bina Pustaka Sarwono Prawirohardjo

Pudiastuti, R. D. 2012. Asuhan Kebidanan Pada Hamil Normal Dan Patologi. Yohyakarta: Nuha Medika

Rahmani, S. L. 2013. Faktor-faktor Resiko Kejadian Abortus Di RS Prikasih Jakarta Selatan Pada Tahun 2013. Jurnal Diakses pada 13 Juli 2017.

Rimanto, F. 2015. Hubungan Abortus Inkomplit dengan Faktor Resiko pada Ibu Hamil di Rumah Sakit Pindad Bandung Periode 2013-2014.Diakses pada tanggal 14 Juli 2017.

Rochjati, P. 2011. Skrining Antenatal dan Komplikasi Kehamilan. Surabaya: Airlangga University Press.

Rochmawati, P. N. 2014. Faktor-Faktor yang MempengaruhiAbortus di
Rumah Sakit Pusat dr. Soeradji Tirtonegoro Klaten. Jurnal. Diakses pada 10 Juli 2017

Sari, N. D. P. 2011. Hubungan Paritas dan Usia Dengan Kejadian Abortus di Ruang Bersalin Rumah Sakit Umum Daerah Dr. Soedarso Pontianak. Diakses pada tanggal 14 Juli 2017.

Saifuddin, A. B. 2014. Ilmu Kebidanan Edisi Keempat. Jakarta: PT Bina Pustaka Sarwono Prawirohardjo

Sibagariang, E. E, dkk.2010. Buku Saku Metodologi Penelitian Untuk Mahasiswa Diploma Kesehatan.Jakarta: Trans Info Media Sugiyono. 2010. Statistika untuk Penelitian. Bandung: Alfabeta

Sugiyono. 2014. Metode Penelitian Kualitatif Kuantitatif $R \& D$. Bandung: Alfabeta

Vita.2015. Jurnal Faktor-Faktor yang Mempengaruhi Terjadinya Abortus di Wilayah Kerja Puskesmas di Kabipaten Gorontalo Utara.Jurusan Keperawatan Fakultas Ilmu Kesehatan dan Keolahragaan Universitas Negeri Gorontalo.Diakses pada tanggal 15 Agustus 2017.

Wadud, M. 2013. Faktor-faktor yang Berhubungan dengan Kejadian Abortus Imminens di Instalasi Rawat Inap Kebidanan Rumah Sakit Muhamadiyah Palembang Tahun 2011.Poltekkes Kemenkes Palembang Jurusan Kebidanan.Diakses pada tanggal 13 Agustus 2017.

Wahyulia.N. (2012). Faktor-faktor yang berhubungan dengan abortus di RSUD dr. Zaonal Abidin banda aceh.Diakses Pada Tanggal 14 Juli 2017.

Wahyuni, H. 2012. Faktor-faktor Risiko yang Berhubungan dengan Kejadian Abortus di Wilayah Puskesmas Sungai Kakap Kabupaten Kubu Raya Kalimantan Barat Tahun 2011.Skripsi Fakultas Kesehatan Masyarakat 
Universitas Indonesia.Diakses pada tanggal 10 Juli 2017.

Wiknjosastro, H. 2008. Ilmu Kebidanan.

Jakarta: PT Bina Pustaka Sarwono

Prawirohardjo 